Original Research Paper

\title{
Effects of Plastic Wedges on Whole Foot Radiograph in Anteroposterior and Oblique Positions
}

\author{
Poe Lorlorm, Winit Choiprasert, Montree Tungjai and Suchart Kothan \\ Department of Radiologic Technology, Faculty of Associated Medical Sciences, \\ Chiang Mai University, Chiang Mai, Thailand 50200, Thailand
}

\author{
Article history \\ Received: 01-01-2017 \\ Revised: 26-03-2017 \\ Accepted: 25-04-2017 \\ Corresponding Author: \\ Suchart Kothan \\ Department of Radiologic \\ Technology, Faculty of \\ Associated Medical Sciences, \\ Chiang Mai University, Chiang \\ Mai, Thailand 50200, Thailand \\ E-mail: suchart.kothan@cmu.ac.th
}

\begin{abstract}
The whole foot radiography may be taken twice with different exposure parameters. It produces two images in two radiation exposures; one is the metatarsal view of the phalange and the other is a tarsal view. The aim of this study was to study the effects of plastic wedges on whole foot radiography with one radiation exposure. The plastic wedge was developed from plastic wood. Whole foot phantom radiographic imaging was created in anteroposterior and oblique positions with and without plastic wedges mounted on the collimator of an X-ray machine. A radiation imaging plate was used as a transmitted-radiation receptor. The radiation exposure parameter was 54 kilo-voltage at 100 milliamperes for $0.02 \mathrm{sec}$. The results showed that the resolution of whole foot phantom radiographic imaging in both anteroposterior and oblique positions with plastic wedge mounted on a collimator of an X-ray machine was better than without plastic wedge mounted on collimator. Percentage of Coefficient Variance $(\% \mathrm{CV})$ of pixel value on radiographic imaging with plastic wedge mounted on collimator was less than without plastic wedge mounted on collimator. This finding suggests that plastic wedges can help improve image quality of whole foot radiography with one radiation exposure.
\end{abstract}

Keywords: Foot Radiography, Plastic Wedge, Image Quality

\section{Introduction}

Injuries or fractures of the foot are quite common. To initially evaluate patients with foot pain, plain radiography is widely used in clinics and in hospitals (Ahn and EL-Khoury, 2007). It plays an important role as a diagnostic tool due to low cost and is less time consuming. The bones of the foot include the phalange, metatarsal and tarsal bones. The density of the phalange and metatarsal bones is less than that of the tarsal bones. Bone density affects radiation attenuation. Consequently, in order to obtain good images of phalange and metatarsal bones, plain radiography involves lower radiation levels than tarsal bone plain radiography. In routine procedures of foot plain radiography, radiologic technologists mostly use anteroposterior or dorsoplantar and oblique positions to show each part of the foot bone. To have whole foot plain radiography, patients must receive four times the radiation for plain film radiography of phalange and metatarsal bones in anteroposterior and oblique views, or for plain film of tarsal bones in anteroposterior and oblique views (Philip, 1995; Frank et al., 2012; Long et al., 2012).
A variety of materials have been used as compensators such as wax (Grabec and Strojan, 2005), plastic (Paliwal et al., 1998) and cement (Thomsen and Ulsø, 2002). In this study, we attempted to use materials for compensating density of foot bones. This compensation was used in order to permit radiation exposures that result in good quality images of the phalange and metatarsal bones plain radiography that are similar to exposures used in tarsal bone plain radiography. Consequently, whole foot plain radiography would involve only two plain films for the anteroposterior and oblique views. Moreover, it was expected that radiation dosage and time spent performing the procedure would decrease. This study used plastic wedges for applications in foot radiography to compensate for density of foot bones.

\section{Materials and Methods}

In order to study radiation absorption coefficients, plastic plates having a thickness of $1.5 \mathrm{~cm}$ were attached to the collimator of an X-ray machine (Quantum medical imaging, Caresteam, Quest HF series). Radiation 
dosages were measured using an ionizing chamber (Capintec 192). The ionizing chamber was placed in the middle of the X-ray beam, at a distance of $60 \mathrm{~cm}$ from the X-ray tube of a medical diagnostic X-ray machine as indicated in Fig. 1.

Radiation absorption coefficient was calculated using the following Equation:

$$
I=I_{0} e^{-\mu X}
$$

When:

$I=$ Transmitted radiation

$I_{0}=$ Incident radiation

$\mu=$ The radiation absorption coefficient

$x=$ Material thickness

In order to study radiation attenuation, plastic wedges developed having a width of $8.9 \mathrm{~cm}$, a length of $11.4 \mathrm{~cm}$ and a thickness of $1.5 \mathrm{~cm}$ as shown in Fig. 2.

The electric potential of the X-ray tube was set to 54 kilo-volts $(\mathrm{kV})$. The X-ray tube current was set at 100 milliamperes $(\mathrm{mA})$ and the time of exposure was 0.02 sec (s)(2 mAs) (Knight, 2014). Plastic wedges were mounted on the collimator of X-ray machines. Radiation imaging plate was used as a transmitted-radiation receptor. Radiation imaging plates were placed in the middle of X-ray beams, at a distance of $100 \mathrm{~cm}$ from the $\mathrm{X}$-ray tube. Image readers created radiographic images from image plates. Pixel value of images was analyzed using Osiris Version 4 programs, to determine the percentage of coefficient variance $(\% \mathrm{CV})$. The $\% \mathrm{CV}$ of pixel value represented the homogeneity of signal intensity of foot phantom radiography.

Radiography without the use of mounted plastic wedges on collimator of X-ray machine is shown in Fig. 3A. It was found that darkness of image was uniform. Radiography equipped with mounted plastic wedges on collimator of X-ray machines is shown in Fig. 3B. It was found that darkness of image was nonuniform due to radiation being attenuated by the plastic wedges. The $\% \mathrm{CV}$ of pixel value in horizontal line on radiography without and with mounted plastic wedges on collimator of X-ray machine were 2.6 and 1.7 respectively (Fig. 3C).
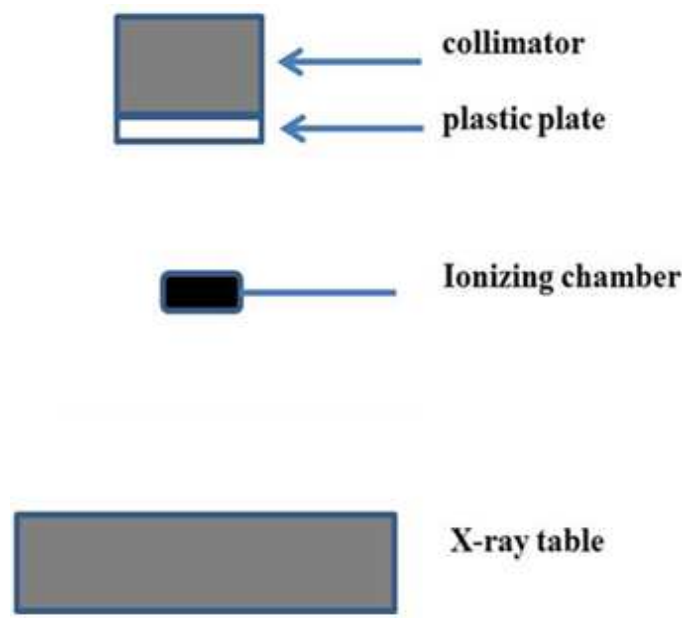

\section{X-ray table}

Fig. 1. Experimental design for determining of radiation absorption coefficient of plastic plate

A

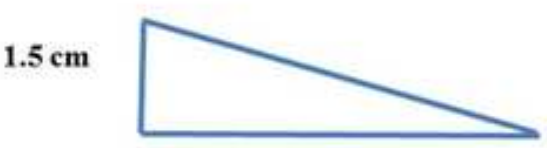

$8.9 \mathrm{~cm}$

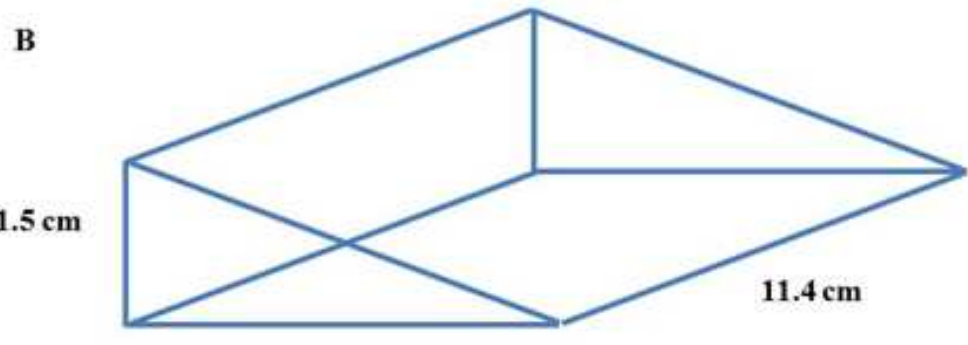

$8.9 \mathrm{~cm}$

Fig. 2. Plastic wood wedge (A) side view, (B) 3D view 

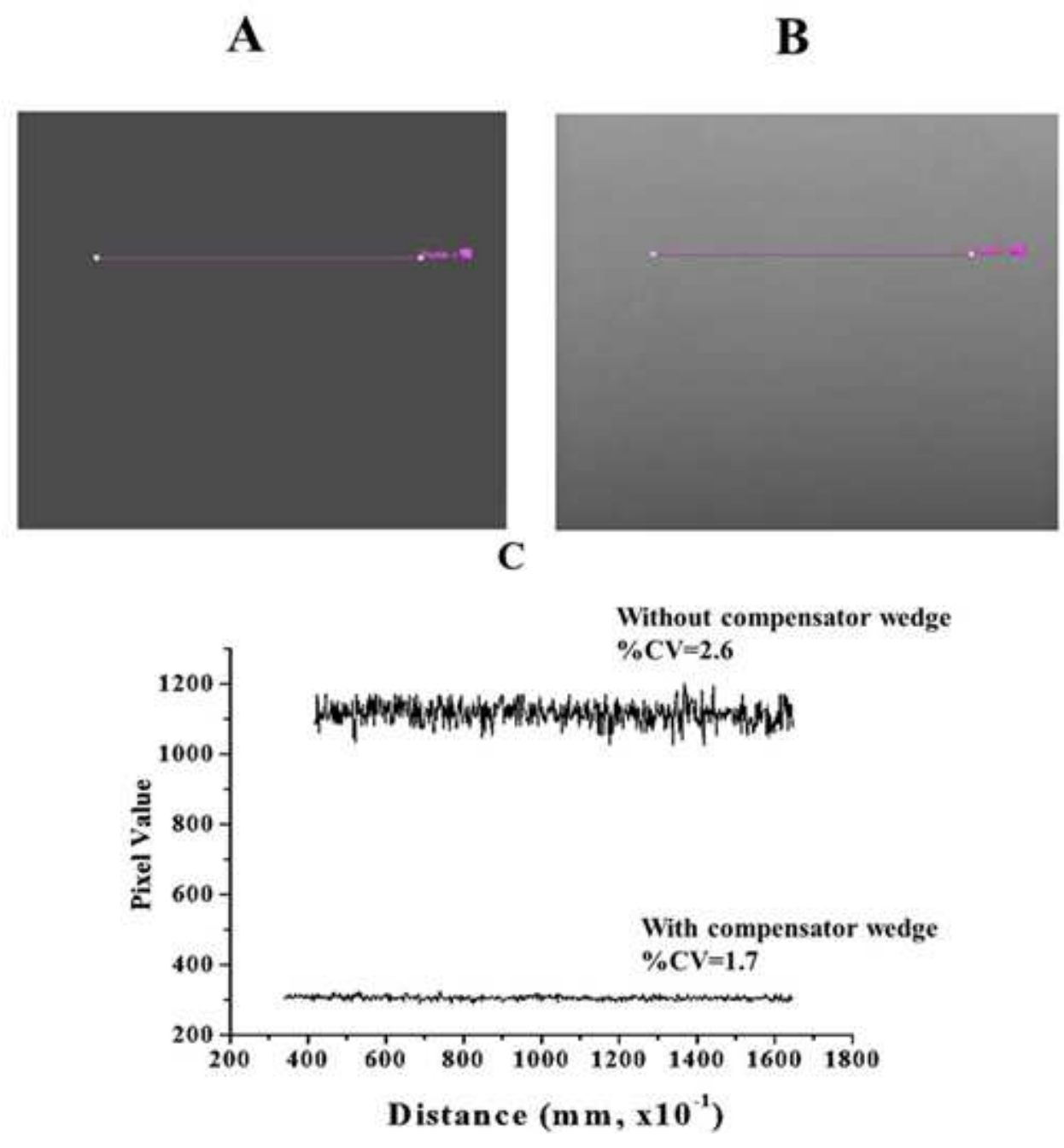

Fig. 3. Radiography image without (A) and with (B) mounted plastic wedge on collimator of X-ray machine. The relationship between pixel values and horizontal line of radiography image without and with mounted plastic wedge (C)

In order to examine signal intensity of foot phantom radiographed in anterior-posterior and oblique positions, the electric potential of X-ray tube was set to $54 \mathrm{kV}$. X-ray tube current was set at 100 $\mathrm{mA}$ and time of exposure was $0.02 \mathrm{~s}$. Plastic wedges were mounted on collimators of an X-ray machine. Radiation imaging plates were placed in the middle of $\mathrm{X}$-ray beam, at a distance of $100 \mathrm{~cm}$ from the X-ray tube of the X-ray machine. Pixel value of image was analyzed by using Osiris Version 4 programs.

\section{Results}

The radiography of foot phantom in anteriorposterior position without and with mounted plastic wedges on collimator of X-ray machine is shown in Fig. 4. The results showed that the resolution of foot phantom image in anterior-posterior position equipped with mounted plastic wedges on collimator of X-ray machine was higher than without mounted plastic wedge on collimator. The $\% \mathrm{CV}$ of pixel value in vertical line of foot phantom image without and with mounted plastic wedge on collimator were 24.8 and 8.7, respectively (Fig. 4C).

The radiograph of foot phantom in oblique position before and after attaching plastic wedge on collimator of X-ray machine is shown in Fig. 5. The results showed that the resolution of foot phantom image in oblique position with mounted plastic wedge on collimator of X-ray machine was higher than without mounted plastic wedge on collimator. The $\% \mathrm{CV}$ of pixel value in vertical line on foot phantom image without and with mounted plastic wedge on collimator were 18.5 and 7.9 , respectively (Fig. 5C). 

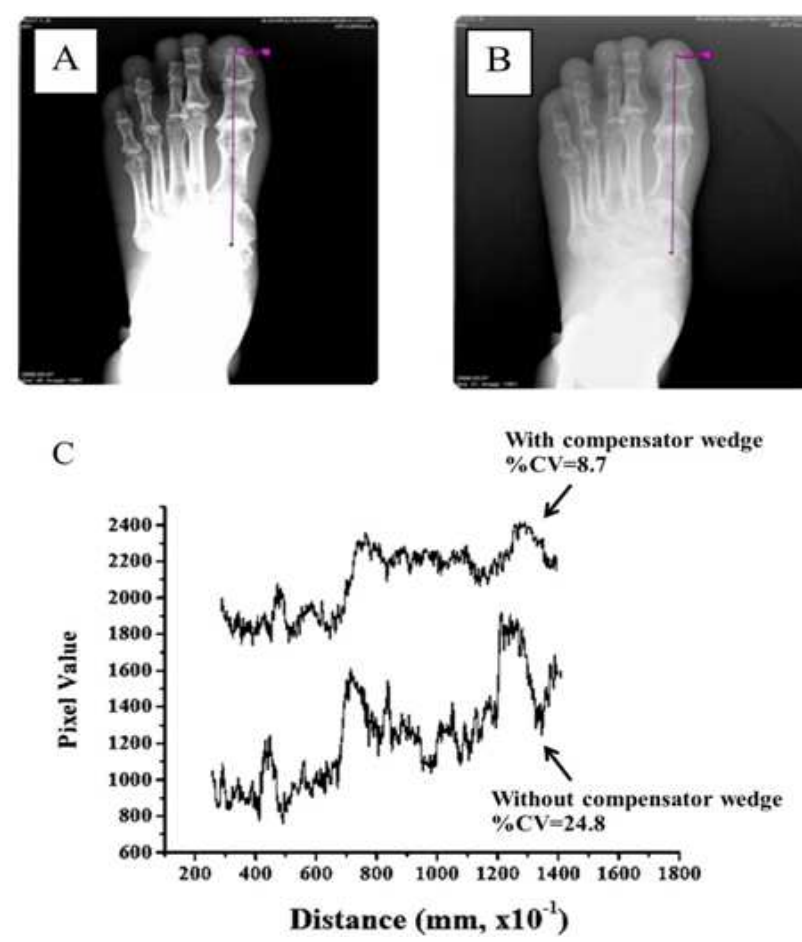

Fig. 4. Foot phantom radiography image in anterior-posterior position without (A) and with mounted plastic wedge on collimator of X-ray machine (B). The relationship between pixel values and vertical line on radiography image without and with mounted plastic wedge $(\mathrm{C})$
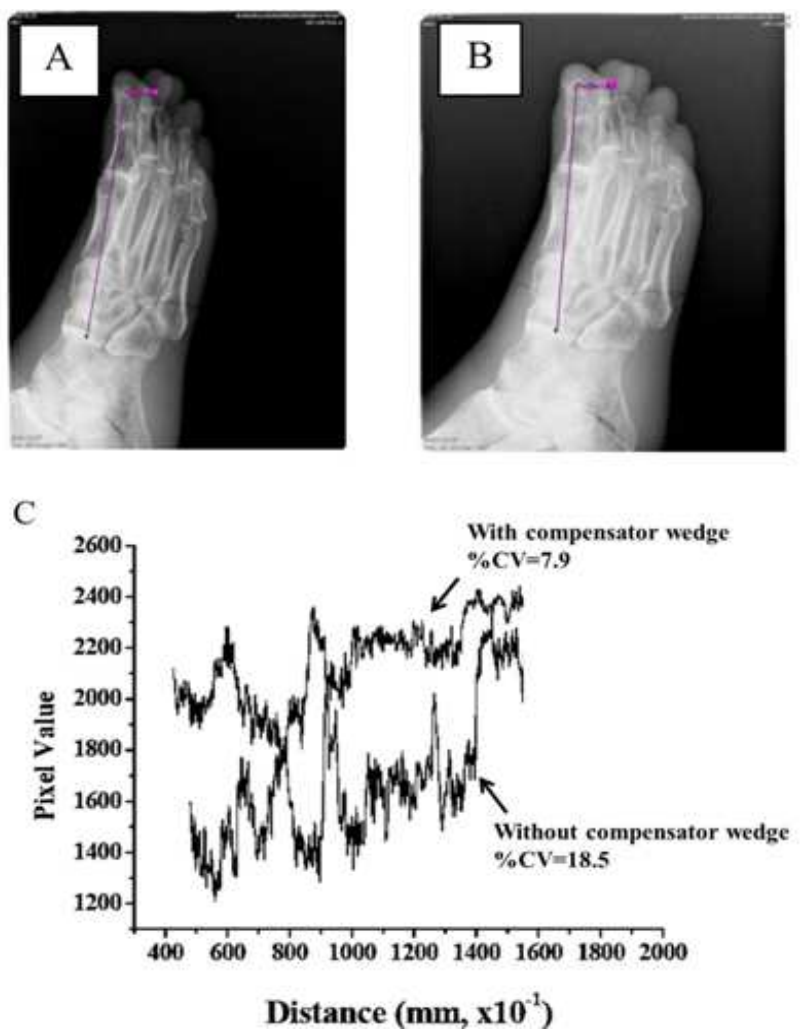

Fig. 5. Foot phantom radiography image in oblique position without (A) and with (B) mounted plastic wedge on collimator of X-ray machine. The relationship between pixel values and vertical line on radiography image without and with mounted plastic wedge (C) 


\section{Discussion and Conclusion}

Foot radiography is commonly used to diagnose foot disease in clinics and hospitals. Foot radiography has to be taken twice using different exposure parameters because foot has different density of element bones. This process produces two images in two exposures; one is the phalange and metatarsal view and the other is tarsal view. It has a disadvantage in that the patient receives double the radiation dosage because the exposure is taken twice. In addition, it increases the time required for the process and the workload of the radiographer. To overcome such a disadvantage, the compensation filter can be applied to foot radiography. The results show that foot radiography can be taken using one exposure parameter, decreases the time required for the process and also decreases the workload of the radiographer. Compensation filters cannot only reduce radiation dosages to patients by absorbing low energy radiation (Manninen et al., 1986), but they also improve radiographic image quality (Gonçalves et al., 2004). Our results show that the plastic wedge can compensate for bone density on phalange and metatarsal regions. Consequently, we used only one exposure for phalange, metatarsal and tarsal view. In addition, our plastic wedges can improve homogeneity of signal intensity of foot radiographic images, resulting in increased resolution of foot bones. Our results corresponded to another authors, as well. Kitagawa and Farman (2004) reported that the Signal-to-Noise Ratio (SNR) of Dexis intraoral radiographic imaging system improved with higher filtration (Kitagawa and Farman, 2004). Wieder and Adams (1981) showed that aluminum filter can improves resolution of chest radiographs. In addition, Jennings et al. (1999) reported that filtration improved imagery of bony structures, provided excellent softtissue visualization and lowered patient exposure. Moreover, the compensating filter was used to improve imaging a spine radiograph. Daud et al. (2014) reported that the compensating filter could increase image quality in lateral projection of thoraco-lumbar radiography. Finally, we concluded that plastic wedge in this study could compensate for foot bone density and improve the homogeneity of signal intensity of foot radiography. Plastic wedge is promising to use as a foot radiographic compensator.

\section{Acknowledgement}

We thank Department of Radiologic Technology, Faculty of Associated Medical Sciences, Chiang Mai University, Thailand for facilities support.

\section{Funding Information}

This research was funded by Department of Radiologic Technology, Faculty of Associated Medical Sciences, Chiang Mai University, Thailand.

\section{Author's Contributions}

Poe Lorlorm: Designed and performed the experiments and generated data.

Winit Choiprasert: Prepared the manuscript

Montree Tungjai: Prepared the manuscript.

Suchart Kothan: Designed and oversaw the experiments, including analyzed data, prepared the manuscript.

\section{Ethics}

There is no conflict of interest regarding the publication of this paper.

\section{References}

Ahn, J.M. and G.Y. EL-Khoury, 2007. Radiologic evaluation of chronic foot pain. Am. Fam. Physician, 76: 975-983. PMID: 17956067

Philip, W.B., 1995. Merrill's Atlas of Radiographic Positions and Radiologic Procedures. 8th Edn., Mosby Year Book, St. Louis, ISBN-10: 0801679362, pp: 626.

Frank, E.D., B.W. Long and B.J. Smith, 2012. Merrill's Atlas of Radiographic Position and Procedures.12th Edn., Elsevier Mosby, Missouri.

Long, B.W., E.D. Frank and R.A. Ehrlich, 2012. Radiography Essentials for Limited Practice. 1st Edn., Elsevier Health Sciences, ISBN-10: 1455740888, pp: 656.

Grabec, D. and P. Strojan, 2005. Missing tissue compensation with wax filter compensators in radiotherapy of the head and neck region. Radiol. Oncol., 39: 219-224.

Paliwal, B.R., S. Rommelfanger and R.K. Das, 1998. Attenuation characteristics of a new compensator material: Thermo-Shield for high energy electron and photon beams. Med. Phys., 25: 484-487.

DOI: $10.1118 / 1.598223$

Thomsen, M.S. and N. Ulsø, 2002. Attenuation of 4-20 MV $\mathrm{X}$ rays by a new compensator material of cement. Med. Phys., 29: 2427-2432. DOI: 10.1118/1.1510129

Knight, S.P., 2014. A paediatric X-ray exposure chart. J. Med. Radiat. Sci., 61: 191-201. PMID: 26229655

Manninen, H., H. Rytkönen, S. Soimakallio, E.O. Terho and J. Hentunen, 1986. Evaluation of ananatomical compensation filter for chest radiography. Br. J. Radiol., 59: 1087-1092. DOI: $10.1259 / 0007-1285-59-707-1087$

Gonçalves, A., J.M.D. de Almeida Rollo, M. Gonçalves, F.H. Neto and F.N. Bóscolo, 2004. Effects of 
aluminum-copper alloy filtration on photon spectra, air kerma rate and image contrast. Braz. Dent. J., 15: 214-219. DOI: 10.1590/S0103-64402004000300010

Kitagawa, H. and A.G. Farman, 2004. Effect of beam energy and filtration on the signal-to-noise ratio of the Dexis intraoral X-ray detector. Dentomaxillofacial Radiol., 33: 21-24. DOI: 10.1259/dmfr/26493631

Wieder, S. and P.L. Adams, 1981. Improved routine chest radiography with a trough filter. Am. J. Roentgenol., 137: 695-698. DOI: 10.2214/ajr.137.4.695
Jennings, M.B., R.E. Cohen, J.P. Marino, M.L. JensisCarlson and A.J. Pollizzi, 1999. Evaluation of compensation filters in pedal radiographs. J. Am. Podiatr. Med. Assoc., 89: 169-173. DOI: $10.7547 / 87507315-89-4-169$

Daud, N.A.A., M.H. Ali, N.A.A. Nazri, N.J. Hamzah and N.A. Awang, 2014. The effect of compensating filter on image quality in lateral projection of thoraco lumbar radiography. J. Phy. Conference Series, 546: 1-7. DOI: $10.1088 / 1742-6596 / 546 / 1 / 012002$ 